\title{
Flame Atomic Absorption Determination of Cobalt in Water After Extraction of its Morpholinedithiocarbamate Complex
}

\author{
Solange Cadore*, Rosemary Dias Goi and Nivaldo Baccan \\ Instituto de Química, Universidade Estadual de Campinas, CP 6154, 13.084-971 Campinas - SP, Brazil
}

\begin{abstract}
Este trabalho descreve um sistema de pré-concentração para cobalto utilizando a resina Amberlyst A-26 modificada com morfolinaditiocarbamato de amônio. O metal foi retido quantitativamente em uma coluna de vidro contendo $1,30 \mathrm{~g}$ da resina modificada com $6 \%(\mathrm{~m} / \mathrm{m})$ de reagente quelante, em $\mathrm{pH}$ 5,5. O complexo colorido formado foi dissolvido com etanol e analisado por espectrometria de absorção atômica com chama em $240,7 \mathrm{~nm}$. A eluição do complexo com $10 \mathrm{~mL}$ de etanol permitiu um fator de pré-concentração igual a 25 , sendo possível a re-utilização de uma mesma coluna. O limite de quantificação obtido foi de $2,0 \mu \mathrm{g} \mathrm{L} \mathrm{L}^{-1}$ com RSD de $2,9 \%$. O estudo de concomitantes mostrou que somente $\mathrm{Cd}(\mathrm{II})$ e $\mathrm{Ni}(\mathrm{II})$ interferem no sistema. O método proposto é simples e de baixo custo, podendo ser usado para determinação de cobalto em águas naturais.
\end{abstract}

A preconcentration system for the determination of cobalt in water was developed. The studied system uses a glass column packed with Amberlyst A-26 resin modified with ammonium morpholinedithiocarbamate. The metal was quantitatively retained in the column containing $1.30 \mathrm{~g}$ of resin modified with $6 \%(\mathrm{~m} / \mathrm{m})$ of chelating reagent, at $\mathrm{pH} 5.5$, resulting in a coloured complex which was eluted with $10.0 \mathrm{~mL}$ of ethanol. The final solution was analysed by flame atomic absorption spectrometry at $240.7 \mathrm{~nm}$. Using these conditions a preconcentration factor of 25 was obtained and depending on the concentration of cobalt present in the solution it was possible to re-utilise the packed column several times. The limit of quantification was $2.0 \mu \mathrm{g} \mathrm{L}^{-1}$ with RSD of $2.9 \%$. The foreign ions effect was studied and only $\mathrm{Cd}(\mathrm{II})$ and $\mathrm{Ni}$ (II) showed interference. The proposed method showed to be simple, of low cost, easy to handle and has been applied for the determination of cobalt in natural water samples.

Keywords: solid-phase extraction, cobalt, water, FAAS

\section{Introduction}

Cobalt is considered an essential ultratrace element to the man because it is a fundamental component of vitamin $\mathrm{B}_{12}$ (Cyanocobalamine), a co-enzyme which takes part on several biological process. Traces of Co are required for utilisation of $\mathrm{Fe}$ in the haemoglobin formation and DNA synthesis and its absence can cause anemia. Problems associated to heart, thyroid and lung can be observed if doses higher than $500 \mathrm{mg}$ were ingested. ${ }^{1}$

There are a variety of methods concerning the determination of trace levels of cobalt demonstrating the importance of this element. One of the most common methods is that based on atomic absorption spectrometry, usually performed after a preconcentration step.

Preconcentration techniques of trace metals, like adsorption by organic reagents fixed on solid materials

* e-mail: cadore@iqm.unicamp.br has been frequently used. The use of silica gel, ${ }^{2,3}$ polyurethane foam, ${ }^{4}$ activated carbon, ${ }^{5}$ naphthalene, ${ }^{6}$ alumina, ${ }^{7}$ and ion exchange resin like $\mathrm{XAD}-2^{8}$ is very common. The metal or the metal-complex is eluted from or dissolved with the support (in the case of naphthalene) by a suitable solvent and afterwards the determination of the metal is performed.

A large number of chelate-forming resins have been prepared and employed for preconcentration studies in the latest years, being used for both off-line or on-line procedures. ${ }^{9}$ This kind of solid material shows great selectivity and sorption capability, mainly for the toxic metals present in waters. ${ }^{10}$

The reaction between the metal ion and the modified resin depends on the nature of chelating group and the selective behaviour of the resin considering the stability of the resultant metal complexes. In some cases however it is advantageous to use a macroporous resin . The Amberlyst 
A-26, an anionic resin, is a macroporous copolymer of styrene that can be modified with a variety of chelating reagents either through electrostatic interactions or by using the resin pore. This resin has been used for the determination of many metals, after suffering modification on its surface. ${ }^{11}$

Reagents such as cupferron, ${ }^{3}$ 1-nitroso-2-naphthol-3,6disulfonate, ${ }^{7}$ and Nitroso R salt, ${ }^{8}$ which react with cobalt ions producing coloured complexes, have been widely used for preconcentration of metals but also the dithiocarbamates are increasingly used for this purpose. ${ }^{4}$ They react with many metallic ions originating coloured complexes. The complexing properties of dithiocarbamates are directly related with the presence of two donor sulphur atoms, which determine the nature of the metals that can bound, and the strength of the formed complexes. Most of the analytically interesting properties occur with disubstituted dithiocarbamates once the monosubstituted compounds show stronger reducing properties and a tendency to decompose to hydrogen sulphide. $^{12}$

According to the properties of the complexes formed, it is possible to classify the dithiocarbamates into three groups: (i) dithiocarbamates with hydrophobic substituents (soluble in organic reagents); (ii) dithiocarbamates with hydrophilic substituents (soluble in water); (iii) dithiocarbamates with two donor $\mathrm{CS}_{2}$ - groups (insoluble in both, water or organic reagents). ${ }^{12}$ The dithiocarbamates from the first group are largely used with analytical aims considering that the formed complexes absorb light over a large spectral range. Morpholine belongs to this group and its use (or its derivative reagents) allows the determination of different kinds of elements.

Morpholine-4-carbodithioate complexes of metals such as nickel, cobalt, iron, cadmium and zinc ${ }^{13}$ as well as complexes of morpholine-dithiocarbamate of rhodium, iridium, palladium and platinum ${ }^{14}$ have been prepared and characterised using magnetic and spectroscopic techniques. Rapid procedures for gravimetric and titrimetric microdetermination of some metals in inorganic and organometallic compounds using morpholinium morpholine-N-dithiocarboxylate have been used ${ }^{15}$ and the determination of zinc, cadmium and lead ${ }^{16}$ (spectrophotometrically) and $\operatorname{arsenic}^{17}$ (by differential pulse polarography) as its morpholine-4-carbodithioates adsorbed on microcrystalline naphthalene have been described.

Considering the lack of information regarding the use of this reagent for solid-phase extraction with other kind of solid material the aim of this work was to develop a preconcentration method for the determination of cobalt in water using Amberlyst A-26 resin modified by ammonium morpholinedithiocarbamate and flame atomic absorption spectrometry.

\section{Experimental}

\section{Apparatus}

The $\mathrm{pH}$-measurements were made by a Procyon $\mathrm{pH}$ meter equipped with a combined glass calomel electrode.

The absorption measurements were made with a PerkinElmer model 5100 PC atomic absorption spectrometer, equipped with a hollow cathode lamp for cobalt as well as a deuterium lamp for background correction, under the following conditions: wavelength: $240.7 \mathrm{~nm}$; slit width: $0.2 \mathrm{~nm}$; lamp current: $30 \mathrm{~mA}$; flame: air/acetylene.

The preconcentration system consisted of glass columns which had a $5 \mathrm{~mm}$ internal diameter in their narrower region and were $25 \mathrm{~cm}$ long. The solution containing the analyte passed through the column, where the resin modified with ammonium morpholinedithiocarbamate was packed.

\section{Reagents}

The Amberlyst A-26 resin, morpholinedithiocarbamate, ethanol, acids and other reagents utilised were of analytical reagent-grade. Deionized water was used throughout.

The cobalt standard solution was prepared from metallic cobalt (J. T. Baker, 99.9\%) treated with $0.5 \%$ (v/v) $\mathrm{HNO}_{3}$ and heat. Appropriate dilution was made from this solution, whenever necessary, with deionized water.

Buffer solutions were prepared by mixing suitable amounts of $0.2 \mathrm{~mol} \mathrm{~L}^{-1}$ acetic acid solution and $0.2 \mathrm{~mol} \mathrm{~L}^{-1}$ ammonium acetate solution.

\section{Preparation of ammonium morpholinedithiocarbamate (MDTC)}

The complexing agent was obtained from the reaction between $21 \mathrm{~mL}$ of carbon disulphide (Merck) and $20 \mathrm{~mL}$ of morpholine (Merck), at $0{ }^{\circ} \mathrm{C}$, under constant stirring. The product was filtered, washed with cold ethanol and recrystallised with ethanol.

\section{Modification of the Amberlyst A-26 resin with ammonium morpholinedithiocarbamate}

An amount of $10 \mathrm{~g}$ of resin was mixed with $0.6 \mathrm{~g}$ of ammonium morpholinedithiocarbamate and $500 \mathrm{~mL}$ of water and it was kept in contact for 12 hours, under slow 
stirring. The efficiency of the resin modification was $99 \%$. In order to confirm this efficiency, the absorbance of the aqueous solution from filtrate was measured in an UV-VIS spectrophotometer, at $284 \mathrm{~nm}$, characteristic for this complexing reagent.

\section{General procedure}

The columns were packed with $1.30 \mathrm{~g}$ of the modified resin and conditioned with $5 \mathrm{~mL}$ of buffer solution at $\mathrm{pH}$ 5.5. An aliquot of the sample solution, containing $30 \mu \mathrm{g}$ of cobalt and $5.0 \mathrm{~mL}$ of buffer solution was taken in a 150 $\mathrm{mL}$ beaker, the $\mathrm{pH}$ was adjusted at 5.5 with diluted nitric acid and ammonia and the solution was diluted to $50 \mathrm{~mL}$ with deionized water. This solution was then passed through the column at a flow rate of $0.3 \mathrm{~mL} \mathrm{~min}^{-1}$, manually controlled.

The cobalt morpholinedithiocarbamate complex, [CoMDTC], formed in the top of the modified resin, as a green ring, was eluted from the column with $10.0 \mathrm{~mL}$ of ethanol. The final solution was aspirated into an air-acetylene flame and the absorbance measured at $240.7 \mathrm{~nm}$ against a similarly prepared reagent blank. To confirm the efficiency of retention on modified resin, the cobalt containing in the solution that had passed throughout the column was also analysed after adequate treatment with concentrated $\mathrm{HNO}_{3}$ and heating.

\section{Samples}

The cobalt content was determined in two different kinds of water: natural water from lake (UNICAMP Campus) and potable water of public reservoir from São José do Rio Preto city (SP, Brazil). Before being used, samples were filtered through a cellulose membrane of $0.45 \mathrm{~mm}$ (Millipore Type HA).

\section{Results and Discussion}

\section{Solid material for preconcentration of cobalt}

Silica gel (non polar) and Amberlyst A-26 (polar) and XAD-4 (non polar) resins, modified with ammonium morpholinedithiocarbamate, have been used in order to establish the adequate solid material for the cobalt preconcentration. The Amberlyst A-26 resin showed the best analytical results, due to the surface modification procedure and to the type of resin, macroporous, which leads to the better interaction between the solid material and the complexing reagent. The mechanism of the modification of the resin may be described as absorption (electrostatic interaction between the resin and the reagent) and adsorption (occlusion of the reagent into resin porous). In the case of silica gel and XAD-4 resin, the interaction with the complexing agent occurs by only an adsorption process, which is less efficient. Figure 1 shows the modification of Amberlyst A-26 with ammonium morpholinedithiocarbamate. Different amounts of the complexing reagent $(2 \%, 4 \%$ and $6 \% \mathrm{~m} / \mathrm{m})$ for the modification of the resin was studied but it was observed no significant difference in the analytical results. The use of $6 \%(\mathrm{~m} / \mathrm{m})$ morpholinedithiocarbamate allows the reutilization of the modified resin for 3 times and also the determination of cobalt ions in the presence of cationic interferents that could compete by the actives sites of complexing agent. a)

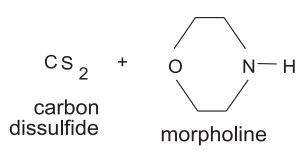

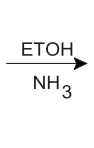

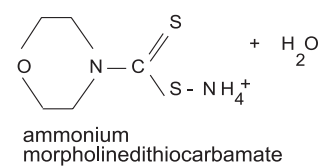

b)
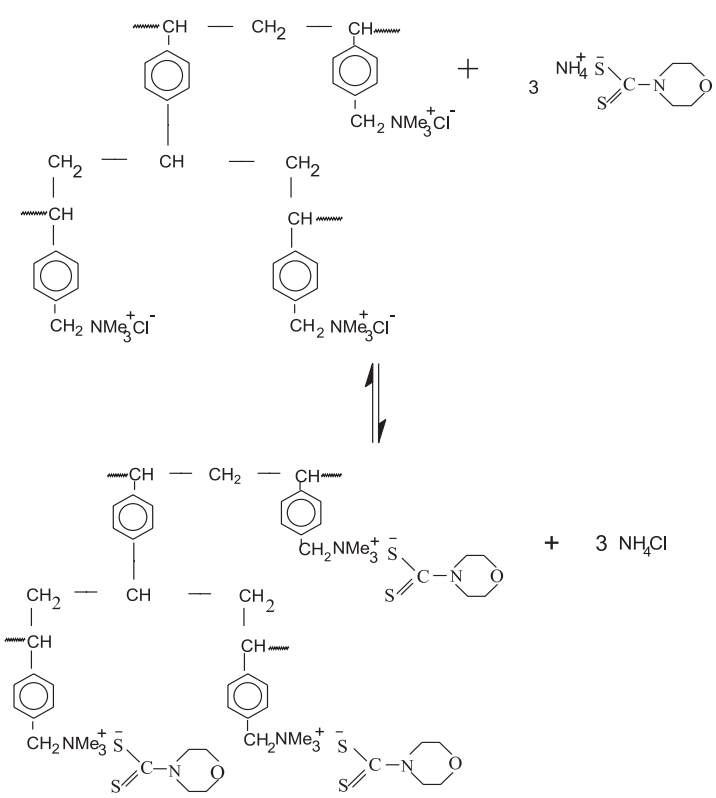

Figure 1. a) Reaction between morpholine and carbon disulfide. b) Modification of Amberlyst A-26 with ammonium morpholinedithiocarbamate.

\section{Solvent for the system}

The appropriate choice of the solvent used for the elution of the formed complex is one of the most important parameters for this kind of analytical method. Characteristics such as the elution capacity of all the column content using a small volume and enhancement of the efficiency of the burner process, mainly when flame atomic absorption spectrometry is used, are required. In this study, ethanol, dimethylformamide, $\mathrm{HCl} 1 \mathrm{~mol} \mathrm{~L}^{-1}$ in 
ethanol and $\mathrm{HCl} 1 \mathrm{~mol} \mathrm{~L}^{-1}$ in dimethylformamide were investigated. The results were quite similar for all the solvents, but the use of ethanol shows some advantages: as it is easy to evaporate the combustion in the flame leads to an increase in the analytical signal for atomic absorption spectrometry; in the presence of hydrochloric acid the complexing reagent is decomposed and $\mathrm{CS}_{2}$ is formed; the reagent (MDTC) is practically insoluble in ethanol while the complex Co-MDTC is soluble, allowing its reutilisation.

\section{Effect of $p H$}

The acidity of the aqueous phase is one of the most important parameters to be investigated on the retention of the analyte in the modified resin, due to the acid-basic properties of the complexing reagent. It permits evaluate the selectivity of the method in the presence of different types of concomitant species, owing to their complexes stability constants. The study of the acidity effect on the recovery of the interested species consisted of the construction of extraction curves (\% of extraction $v s . \mathrm{pH}$ ) and its effect over the range 1.0 to 10.0 is showed in Figure 2. In acidic medium ( $\mathrm{pH}$ less than 4.0) the possibility of the dithiocarbamate decomposition in $\mathrm{H}_{2} \mathrm{~S}$ and $\mathrm{CS}_{2}$ is well known. ${ }^{12}$ On the other hand, $\mathrm{pH}$ higher than 8.0 leads to the formation of cobalt hydroxide. Between $\mathrm{pH} 4.0$ and 6.0 the extraction showed to be complete and a value of 5.5 was chosen for the remaining studies. In order to maintain this $\mathrm{pH}$ value a buffer solution of acetic acidammonium acetate is recommended.

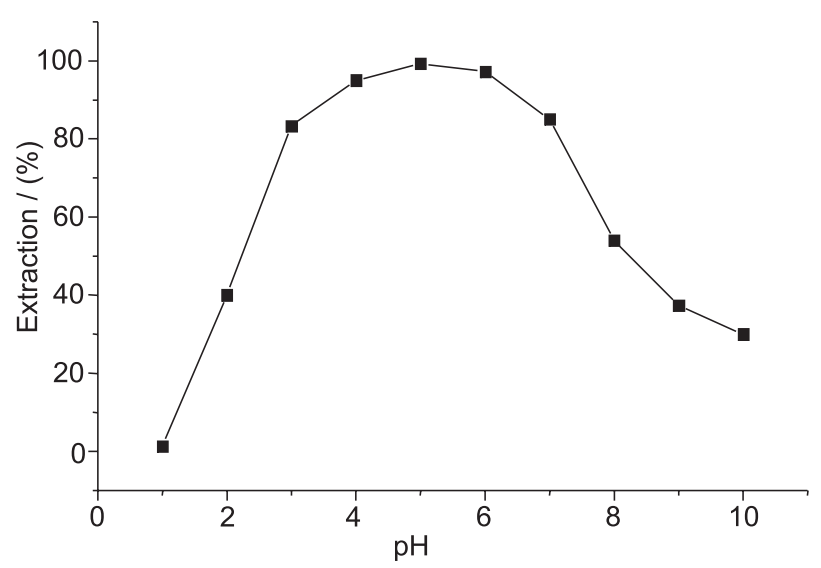

Figure 2. Effect of $\mathrm{pH}$ on the determination of Co.

Study of sample flow rate

The efficiency of the Co-MDTC complex formation depends on the interaction between cobalt and the complexing reagent as a result of the time they keep contact. It means that the flow rate utilised for the passage of the sample through the column may affect this interaction. In this study it was observed that a flow rate of $0.3 \mathrm{~mL} \mathrm{~min}^{-1}$ allowing recovery of Co higher than $99.0 \%$. It was also observed that when a flow rate higher than $0.5 \mathrm{~mL} \mathrm{~min}{ }^{-1}$ was used, the green ring corresponding to the complex was not formed on the top of the column but it was spread over all of it.

\section{Study of the column capacity}

The column capacity was evaluated by two different ways: its capacity considering the aqueous phase volume which passes through the column and the amount of analyte which is retained by it.

Considering different types of samples and the concentration of the studied species, the utilisation of a great amount of sample is sometimes necessary in order to reach the detection limit of the technique. In this study it was observed that $30 \mu \mathrm{g}$ of cobalt contained in volumes of up to $250 \mathrm{~mL}$ could pass through the column without affecting its extraction. Higher volumes decrease significantly the extraction and increase the time spent in the analysis. Using such sample volume and eluting the complex with $25.0 \mathrm{~mL}$ of ethanol it was possible to obtain a pre-concentration factor of 10 . However, a factor of 25 was reached considering the passage of $250 \mathrm{~mL}$ sample through the column and its elution with $10.0 \mathrm{~mL}$ of ethanol. Otherwise, it is possible to evaluate de column capacity considering the amount of solute necessary to saturate it, that is, the maximum quantity of metal which can be retained by the amount of MDTC present in the modified resin. In this case, increased quantities of Co were introduced into the column. By the stoichiometric relation of 1:3 (Co:MDTC), it is necessary an amount of $9469 \mathrm{mg}$ of cobalt to saturate the column but experimental data showed the complete recovery of cobalt only when quantities up to $1500 \mathrm{mg}$ are added. That means that the column capacity was $20 \mu \mathrm{mol} \mathrm{g} \mathrm{g}^{-1}$ of modified resin. It is reasonable to suppose that the interaction between cobalt and the complexing reagent have an increasing difficulty while the reaction occurs.

\section{Column re-utilisation}

As it has already been described, a green ring is formed in the top of the column, when cobalt is added in the system and this "ring" disappears by the passage of the eluent. In order to increase the analytical speed of the method, it was made a study for the re-utilisation of the material contained in the column. The extraction of cobalt is total even after the introduction of three different samples, if the column 
was washed with $10.0 \mathrm{~mL}$ of ethanol and $50.0 \mathrm{~mL}$ of desionised water between their introduction. It was interesting to note that the "ring" of the complex were formed each time in different position, below the former. It confirms that the metal complex, and not only the metal, is eluted by ethanol, without removing the free reagent fixed by electrostatic charge on the surface of the resin.

\section{Study of interferents}

It is well known that cobalt determination is affected by some metallic ions when morpholinedithiocarbamate is utilised as a complexing reagent. If MDTC complexes with the interfering species in the same $\mathrm{pH}$ range established for the Co determination, the available amount of complexing agent will be reduced, resulting in a reduction of the extraction efficiency. In this study it was important to evaluate the effect of these ions considering: the green complexes formed by nickel, cadmium and bismuth; the dark brown complexes of copper and iron; the white complexes of zinc and lead as well as the colourless complex of manganese. This study was developed by spiking solutions containing $30 \mathrm{mg}$ of cobalt with an excess of $\mathrm{Mn}^{2+}, \mathrm{Ni}^{2+}, \mathrm{Bi}^{3+}, \mathrm{Fe}^{2+}, \mathrm{Fe}^{3+}, \mathrm{Cd}^{2+}, \mathrm{Cu}^{2+}$, $\mathrm{Zn}^{2+}$ and $\mathrm{Pb}^{2+}$. Amounts of up to $1000 \mu \mathrm{g}$ was used for the investigated ions, and this value was established by the metal:ligand stoichiometry and mainly by the column saturation, considering the amount of the adsorbent material utilised. It was observed that manganese, bismuth and iron do not interfere. Otherwise, in the presence of 500 $\mu \mathrm{g}$ of zinc or lead, the analytical signal decreased $6 \%$, while the effect of cadmium and nickel significantly influence the extraction of cobalt (the maximum amount tolerated for these species was 200 and $100 \mu \mathrm{g}$, respectively). The elution of Co-MDTC complex is quantitative even in the presence of $500 \mathrm{mg}$ of copper but the brown complex Cu-MDTC remains in the column demanding a solution of $3 \mathrm{~mol} \mathrm{~L}^{-1} \mathrm{HNO}_{3}$ to eluted it. In the presence of other ions, mainly iron, it is advisable to add a solution of ammonium tartrate, in order to avoid hydrolysis. Anions present in the acid utilised for sample treatment were investigated but there was no significant effect on cobalt extraction.

The interference of cadmium may be overcome by using potassium iodide. Considering the similar chemical behaviour of nickel and cobalt, it is very difficult to find some reagent selective to only one of them.

\section{Figures of merit}

Considering that it is possible to retain $0.5 \mu \mathrm{g}$ of cobalt from $250 \mathrm{~mL}$ of solution passing through the column and to elute the complex with $10.0 \mathrm{~mL}$ of ethanol, at a flow rate of $0.3 \mathrm{~mL} \mathrm{~min}^{-1}$, the limit of determination is $2.0 \mu \mathrm{g}$ $\mathrm{L}^{-1}$ and the enrichment factor is 25 . The precision, expressed as a relative standard deviation is $2.9 \%(\mathrm{n}=10)$ evaluated for a cobalt solution containing $3.6 \mu \mathrm{g} \mathrm{L}^{-1}$. The accuracy of the proposed preconcentration procedure was evaluated by means of cobalt determination using graphite furnace atomic absorption spectrometry.

\section{Samples}

The method was evaluated by analysis of water from different origins. Considering the low content of cobalt present in the samples they were enriched with the metal and its recovery was evaluated. Table 1 shows the concentration of cobalt obtained with the proposed method, when $100 \mathrm{~mL}$ of sample was analysed in the presence of $0.4 \mathrm{~mL}$ of $2.5 \%(\mathrm{~m} / \mathrm{m})$ ammonium tartrate. These results were in agreement with those obtained with graphite furnace.

\section{Conclusions}

The procedure to obtain the reagent (MDTC) and to modify the resin is very simple. The proposed methodology for preconcentration of cobalt with ammonium

Table 1. Determination of cobalt in natural water samples $(n=3)$

\begin{tabular}{|c|c|c|c|c|}
\hline Sample & Cobalt added (mg) & Recovery $(\%)$ & Proposed method $\left(\mu \mathrm{g} \mathrm{L}^{-1}\right)$ & GF AAS $\left(\mu \mathrm{g} \mathrm{L}^{-1}\right)$ \\
\hline \multirow[t]{5}{*}{ UNICAMP lake (SP) } & 0 & & $3.7 \pm 0.3$ & $3.3 \pm 0.5$ \\
\hline & 5 & 98 & & \\
\hline & 10 & 98 & & \\
\hline & 20 & 99 & & \\
\hline & 30 & 99 & & \\
\hline \multirow{5}{*}{$\begin{array}{l}\text { Drinking water São José } \\
\text { do Rio Preto (SP) }\end{array}$} & 0 & & $2.4 \pm 0.4$ & $2.3 \pm 0.3$ \\
\hline & 5 & 98 & & \\
\hline & 10 & 99 & & \\
\hline & 20 & 99 & & \\
\hline & 30 & 98 & & \\
\hline
\end{tabular}


morpholinedithiocarbamate is simple but not so rapid, it is of low cost, mainly considering the possibility of the reutilization of the solid material. The enrichment factor obtained allows the determination of cobalt in natural waters.

\section{Acknowledgements}

R.D.G. acknowledges the grant from CNPq (Brazil). We are grateful to Dr. Carol H. Collins for critically reading the manuscript.

\section{References}

1. Tsalev, D.L.; Zaprianov, Z. K.; Atomic Absorption Spectrometry in Occupational and Environmental Health Practice, CRC Press Inc.: Boca Raton, Florida, 1984, vol. 1.

2. Matoso, E.; Kubota, L. T.; Cadore, S.; Talanta 2003, 60, 1105.

3. Bortoleto, G. G.; Macarovscha, G.; Cadore, S.; J. Braz. Chem. Soc. 2004, 15, 313.

4. Sant'Ana, O. D.; Jesuino, L. S.; Cassella, R. J.; Carvalho, M. S.; Santelli, R.E.; J. Braz. Chem. Soc. 2003, 14, 728.

5. Yaman, M.; Güçer, S.; Analusis 1995, 23, 168.

6. Costa, A. C. S.; Lopes, L.; Korn, M. G.; Portela, J. G.; J. Braz. Chem. Soc. 2002, 13, 674.
7. Trojanowicz, M.; Pyrzynska, K.; Anal. Chim. Acta 1994, 287, 247.

8. Lemos, V. A.; Santos, J. S.; de Carvalho, M. B.; Baliza, P. X.; Yamaki, R. T.; Anal. Chim. Acta 2003, 494, 87.

9. Torre, M.; Marina, M. L.; Crit. Rev. Anal. Chem. 1994, 24, 327.

10. Jain, V.K.; Sait, S.; Shrivastav, P.; Agrawal, Y.K.; Talanta 1997, 45, 397.

11. Brajter, K.; Olbrych-Sleszynska, E.; Talanta 1983, 30, 355.

12. Hulanicki, A.; Talanta 1967, 14, 1371.

13. Aravamudam, G.; Brown, D. H.; Venkappayya, D.; J. Chem. Soc. A 1971, 17, 2744.

14. Marcotrigiano, G.; Pellacani, G. C.; Preti, C.; Tosi, G.; Bull. Chem. Soc. Jpn. 1975, 48, 1018.

15. Sakla, A. B.; Helmy, A. A.; Beyer W.; Harhash, F. E.; Talanta 1979, 26, 519.

16. Sethi, C. L.; Puri, B.K.; Satake, M.; Microchem. J. 1986, 33, 179.

17. Puri, S.; Dubey, R. K.; Gupta, M. K.; Puri, B. K.; Talanta 1998, 46, 655 .

Received: February 14, 2005

Published on the web: July 27, 2005

FAPESP helped in meeting the publication costs of this article. 